\section{Psychological and physiological effects of emotion focused training for self-compassion and self-protection}

\author{
Júlia Halamová, ${ }^{1}$ Jana Koróniová, ${ }^{1}$ Martin Kanovský, ${ }^{2}$ \\ Mária Kénesy Túniyová, ${ }^{3}$ Nuriye Kupeli ${ }^{4}$ \\ ${ }^{1}$ Institute of Applied Psychology, Faculty of Social and \\ Economic Sciences, Comenius University in Bratislava, \\ Bratislava, Slovakia; ${ }^{2}$ Institute of Social Anthropology, \\ Faculty of Social and Economic Sciences, Comenius University \\ in Bratislava, Bratislava, Slovakia; ${ }^{3}$ Institute of Experimental \\ Psychology, Center of Social and Psychological Sciences, \\ Slovak Academy of Sciences, Bratislava, Slovakia; ${ }^{4}$ Marie Curie \\ Palliative Care Research Department, Division of Psychiatry, \\ University College London, London, United Kingdom
}

\begin{abstract}
Emotion Focused Training for Self-Compassion and Self-Protection (EFT-SCP) is a novel intervention developed on the basis of the latest findings on self-criticism from Emotion-focused therapy and existing programs designed to cultivate compassion. EFTSCP is designed to encourage participants to cultivate self-compassion and protective anger as a way of reducing selfcriticism. Our goal was to investigate the effect of this group-based intervention on self-criticism, self-protection, and self-compassion. A total of 73 students were assigned to the EFT-SCP intervention $(n=19)$, no-treatment control $(n=34)$ or to an active control group $(n=20)$. The intervention group met weekly for 1.5 hours and were instructed to incorporate EFT-SCP tasks into their daily life for 12 weeks. Whilst the no-treatment group did not undergo an intervention, the active control group completed an adapted expressive writing task once a week. In addition to the assessment of heart rate variability during imagery tasks, participants also completed self-reported measures of self-compassion and self-criticism before and after the intervention. Compared with both control groups, the intervention group showed a significant increase in heart rate variability following EFT-SCP (during self-critical imagery, $\mathrm{P}=.049$; probability of superiority was .63 , and during self-compassionate imagery $\mathrm{P}=.007$; probability of superiority was .62 , both effect sizes were medium) and significant decreases in selfcriticism (Hated Self $\mathrm{P}=.017 ; .34$ and Inadequate Self $\mathrm{P}<.001 ; .33$ ) and self-uncompassionate responding $(\mathrm{P}<.001 ; .39)$. All three effect sizes were small. Participating in EFT-SCP had a positive effect on psychological and physiological outcomes.
\end{abstract}

Key words: Self-criticism; Self-reassurance, Self-compassion; Emotion-focused therapy; Heart rate variablity; Intervention.

\section{Introduction}

Self-compassion and self-criticism are opposite ways of relating to the self: self-criticim is the experience of
Correspondence: Julia Halamová, Institute of Applied Psychology, Faculty of Social and Economic Sciences, Comenius University in Bratislava, Mlynské luhy 4, 82105 Bratislava, Slovakia. Tel.: 00421908604141.

E-mail: julia.halamova@gmail.com

Citation: Halamová, J., Koróniová, J., Kanovský, M., Kénesy Túniyová, M., \& Kupeli, N. (2019). Psychological and physiological effects of emotion focused training for self-compassion and self-protection. Research in Psychotherapy: Psychopathology, Process and Outcome, 22(2), 265-280. doi: 10.4081/ripppo.2019.358

See online Appendix for additional Tables.

Acknowledgements: the authors would like to acknowledge Dominika Sellárová, Romana Sládkovičová, and Stanislava Todorovič for help with data collection and Slovak Academy of Sciences for borrowing BIOPAC. In addition, they would like to acknowledge Bronislava Strnádelová and Martina Baránková for delivering the intervention.

Contributions: JH designed and executed the study, created the intervention, coordinated research team, and wrote the paper; JK collaborated with the design, collected data, and wrote the paper; MK prepared data for analysis, performed statistical analysis, and wrote the paper. MKT collaborated with the data collection, with data preparation, and with writing the paper; NK collaborated with the writing and editing of the manuscript. All authors interpreted the results, revised the manuscript and read and approved the final version of the manuscript.

Conflict of interest: the authors declare no potential conflict of interest.

Funding: this work was supported by the Vedecká grantová agentúra VEGA under Grant 1/0075/19. Nuriye Kupeli is supported by Alzheimer's Society Junior Fellowship grant (Grant award number: 399 AS-JF-17b-016).

Ethical approval: all procedures performed in studies involving human participants were in accordance with the ethical standards of the institutional and/or national research committee and with the 1964 Helsinki declaration and its later amendments or comparable ethical standards.

Informed consent: written informed consent was obtained from all individual participants included in the study.

Availability of data and materials: in order to comply with the ethical approval of the study protocols, data cannot be made accessible through a public repository. However, data are available upon request for researchers who consent to adhering to the ethical regulations for confidential data.

Received for publication: 11 December 2018

Revision received: 8 March 2019

Accepted for publication: 26 April 2019.

This work is licensed under a Creative Commons Attribution NonCommercial 4.0 License (CC BY-NC 4.0).

${ }^{\circ}$ Copyright: the Author(s), 2019

Licensee PAGEPress, Italy

Research in Psychotherapy:

Psychopathology, Process and Outcome 2019; 22:265-280

doi:10.4081/ripppo.2019.358 
inner suffering while self-compassion is a form of alleviating inner as well as external pain. Blatt and Zuroff (1992) described self-criticism as constant and harsh selfscrutiny and self-appraisal accompanied with the experience of unworthiness, inferiority, failure, and guilt while self-compassion is defined as a sensitivity to detect one's own pain together with motivation and actions to alleviate and prevent it (Gilbert \& Choden, 2013). High self-criticism and low self-compassion are generally linked with higher incidence of psychopathology (Shahar et al., 2012) while high self-compassion and low self-criticism are related to greater mental health and happier life (MacBeth \& Gumley, 2012; Zessin, Dickhāuser, \& Garbade, 2015). Therefore, these constructs are clinically meaningful and thus research on interventions which can increase selfcompassion and decrease self-criticism are essential. Although the two constructs are usually described in terms of personality traits (e.g. Svendsen et al., 2016; Zuroff, Mongrain, \& Santor, 2004), research has shown that these characteristics are amenable to change (e.g. Gilbert \& Procter, 2006). To date, several interventions have been designed to help individuals to cultivate compassion and thus alleviate self-criticism. According to Kirby (2017), there are eight established compassion-based intervention programs including Compassionate Mind Training (CMT; Gilbert, 2009, 2010a, 2010b) and Mindful Self-Compassion training (MSC; Neff \& Germer, 2013). A more recently developed intervention is Emotion Focused Training for Self-Compassion and Self-Protection (EFTSCP; Halamová, Kanovský, Varšová, \& Kupeli, 2018).

\section{Emotion focused training for self-compassion and self- protection}

More recently, self-compassion has become a widely explored phenomenon. As defined by Neff (2012) selfcompassion represents an ability to treat oneself with love, support and understanding even during experiences of failure and suffering. Gilbert (2010a) has suggested that self-compassion is a motivation to care about oneself. This also includes the ability to tolerate and endure negative emotions as a result of negative life events. It is also important to understand, that being self-compassionate does not automatically mean the absence of negative emotions or failures, but rather, it enables us to cope with them more effectively (Marshall et al., 2015).

Some authors refer to self-compassion as a protective mechanism in context of maintainning mental health (Muris, Meesters, Prierik, \& Kock, 2015) by engaging protective anger (e.g Timulak, 2015). In these terms, protective anger is a reaction to unmet needs and emotional pain which is thought to equip oneself with assertiveness to respond to mistreatment (Timulak \& Pascual-Leone, 2014). On the other hand, reactive anger, which, in contrast to protective anger, is characterised by irritability and reactivity to others behavior (Pascual-Leone, Gillis, Singh, \& Andreescu, 2013). Pascual-Leone and Green- berg (2007) stress, that if a person is self-critical, therefore has a poor self-evaluation, generating protective anger or even self-compassion might be very difficult. On the other hand, being able to generate assertive anger and self-compassion may facilitate one to set boundaries (Timulak \& McElvaney, 2015).

EFT-SCP (Halamová, Kanovský, Varšová, \& Kupeli, 2018) is an intervention designed to teach individuals ways to increase self-compassion and decrease self-criticism, concurrently. This new intervention was developed on the basis of the latest findings on self-criticism from Emotion-focused therapy and previous programs cultivating compassion (mainly programs such as CMT and MSC). To deliver EFT-SCP, this study used the simple and light touch expressive writing paradigm which involves writing about emotionally inducing experiences for 15-20 minutes on 3-4 consecutive days (Pennebaker, 2017; Pennebaker \& Beall, 1986).

The uniqueness of EFT-SCP training is in building self-compassion along with developing protective anger to combat self-criticism. Building protective (assertive) anger is particularly important in self-compassion training, because people who lack self-compassion may sometimes be submissive, not able to stand up for themselves (Akin, 2009), and their self-assesment tends to be negative and critical (Neff, Kirkpatrick, \& Rude, 2007). The intervention builds on Emotion-focused therapy theory and applies techniques from psychotherapy to non-psychotherapeutical settings as a simple and accessible intervention to address self-criticism.

In Emotion-focused therapy, therapists coach clients towards primary adaptive emotions that are attended to and expressed in therapy in order to access the adaptive information and action tendency to guide problem solving (Elliott, Watson, Goldman, \& Greenberg, 2004, p. 31). This approach addresses self-criticism by tapping into two primary adaptive feelings. The first is protective anger which can occur when people feel they are mistreated and are motivated to stand against the dismissive other (in this case the self-critic) by taking assertive actions to set boundaries and stop the mistreatment. The second primary adaptive emotional response is self-compassion. Generally, people feel compassion when they are faced with suffering even towards the self and it motivates them to take actions to alleviate the suffering.

Studies evaluating EFT suggest that self-criticism can be targeted and reduced by accessing both protective anger at mistreatment and self-compassion in the face of pain and suffering (Greenberg, 2011; Timulak, 2015; Timulak \& Pascual-Leone, 2014). To date, the effectiveness of this treatment in targeting self-criticism is supported by evidence from research studies evaluating this approach during psychotherapeutic sessions with patients in clinical settings (Greenberg \& Watson, 2005). However, the importance of targeting protective anger and self-compassion in addressing self-criticism beyond psychotherapy and in nonclinical 
populations has also been documented (Kelly, Zuroff, \& Shapira, 2008; Whelton \& Greenberg, 2005). Therefore, protective anger is considered to be a healthy way of expressing anger, because it validates that it is painful to have needs unmet. The EFT model highlights the need to cultivate both protective anger and self-compassion in the process of self-criticism reduction (Timulak, 2015).

In a study of self-criticism, those who reported more contempt, shame and disgust and less resilience and anger in response to their self-criticism, were more self-critical (Whelton \& Greenberg, 2005). All participants were able to be self-critical but only highly self-critical participants were not able to address their own self-criticism, meaning they may have faced their negative self-evaluations with submission. Participants in a study using two different self-help interventions benefited more from the attack-resisting condition and self-compassionate condition compared to the control condition (Kelly et al., 2008). Kelly et al. (2008) did not combine self-soothing and attack-resisting interventions together and therefore they were not able to test the effects of a combined treatment. Authors recommended testing an intervention combining selfcompassionate and self-attack resistance learning.

Currently, compassion-based interventions have focused primarily on developing compassion and self-compassion, but these programs do not directly address the need to build assertive reactions that would elicit protective anger to address one's own self-critic (Kirby, 2017). Therefore, we have used recent developments in the field of interventions that support self-compassion (mainly programs including CMT and MSC program) and Emotion-focused therapy to design a new self-compassion intervention. Preliminary results of a randomized control trial assessing the effects of EFT-SCP on self-compassion (as assessed by the Self-Compassion Scale; Neff, 2003) and self-criticism/reassurance (subscales of the Forms of Self-Criticising/Attacking \& Self-Reassuring Scale, FSCRS; Gilbert, Clark, Hempel, Miles, \& Irons, 2004) have been reported elsewhere (Halamová, Kanovský, Varšová, \& Kupeli, 2018). In summary, this study suggests that a short-term online version of EFT-SCP showed promising results with significant effects of EFT-SCP in increasing self-compassion and self-reassurance scores as well as decreasing self-uncompassionate responding and self-criticism over two months in a community sample. This study used various methods of delivering the intervention such as letter writing and selfcompassionate mirror but this study did not use guided imagery as a method of delivering the therapeutic tasks.

\section{Guided imagery}

Imagery is an extensively used method in psychotherapy including compassion-based interventions (e.g. Leighton \& Halifax, 2003; Rockliff, Gilbert, \& McEwan, 2008), because it is suggested to influence a change in emotions and physiological states (Hackmann \& Holmes, 2004). Lang, Kozak, Miller, Levin, and McLean (1980) explains, that emotional imagery does not need exteroceptive input to occur, during guided imagery the brain is activated similar to if there is an actual perceptual experience. Gilbert (2010a) posits that this is because our brain is not very proficient in distinguishing between an actual perceptual stimulus and imagery. A classic example of this is automatic salivation during thoughts of food. Similarly, imagery can trigger strong emotional responses and can be used as a method for stimulating self-compassion and self-reassurance by triggering memories of soothing and reassuring experiences (Gilbert et al., 2004; Neff, 2011). Gilbert and Irons (2004) posit that self-criticism can influence one's ability to recall the self-reassuring and self-soothing inner voice. Mayhew and Gilbert (2008) demonstrated that using self-compassionate imagery in self-critical people led to a decrease in depression, psychoticism, anxiety, paranoia and obsessivecompulsive disorder symptoms. Gilbert and Procter (2006) highlight that self-compassionate imagery can be particularly useful for highly self-critical people who believe they are ultimately flawed and do not deserve compassion, because using this technique helps them to minimise their habitual inner voice of self-criticism. As the imagery imitates physiological responses to similar real-life situations, measures of physiological change, such as heart rate variability (HRV) may provide a useful way to assess the effect of compassion-based interventions.

\section{Heart rate variability}

HRV indicates the time variation in the intervals between successive heart beats (also referred to as inter-beat and R-R intervals). Higher levels of HRV at rest is a physiological indication of good health and of a person's ability to respond to stress and regulate their emotional response to challenging experiences (Park \& Thayer, 2014). HRV is an assessment of the autonomic nervous system and serves as an indicator of the activation of the sympathetic and parasympathetic systems. HRV assessment can provide an indication to which system is dominant (Javorka, 2008). Parasympatic activity regulates the fight or flight response and therefore helps us to achieve feelings of calm and safety mainly through prosocial behavior and care towards oneself and others (Gilbert, 2014). HRV is dependent on a number of internal and external factors including but not limited to, physical activity, emotions and stress. Endogenous influences on HRV include respiratory sinus arrhythmia (Yasuma \& Hayano, 2004), baroreceptor and chemoreceptor regulations (Akselrod et al., 1981), partial pressure carbon dioxide and respiratory rate (Pöyhönen, Syväoja, Hartikainen, Ruokonen, \& Takala, 2003), or other influences such as the neuroendocrine system and circadian variation (Silverman, Heim, Nater, Marques, \& Sternberg, 2010).

Pool (1989) claims that variability of body systems is connected to better overall health (e.g. heart system). Therefore, whilst high HRV reflects a healthy functioning heart and is a sign of optimal ability to adapt to a changing 
environment, reduced HRV means the system is experiencing stress, and may contribute to cardiovascular disease (Kemp \& Quintana, 2013). The relationship between HRV and psychological health has also been well documented. There is evidence that reduced HRV is related to an increased tendency to worry, depression and impaired sleep (e.g. Borrione et al., 2018; Jackowska et al., 2012).

Various studies have showen how external factors can influence HRV. For example, inducing emotions of anger during recollection of difficult experiences has been shown to significantly increase the sympathetic activation, which is also responsible for increasing heart rate. In contrast inducing appreciation generated balanced or an increase in parasympathetic activity (McCraty, Atkinson, Tiller, Rein, \& Watkins, 1995). Parasympathetic activity and HRV can be increased consciously through strategies such as breathing, using a soft voice, or facial expressions and body postures (Bornemann, Kok, Bockler, \& Singer, 2016) which have been suggested to promote the experience of calmness and relaxation (Krygier et al., 2013). The use of simple tasks such as controlled breathing opens the door for therapeutic interventions to increase HRV through specific breathing and relaxation (Lehrer \& Gevirtz, 2014). Based on these psychophysiological findings, it can be suggested that by promoting relaxation, meditation or cultivating compassion, one should experience a positive effect on HRV (i.e., greater HRV).

There is an increasing emphasis for researchers to use physiological measures such as HRV in addition to selfreport measures when evaluating the impact of interventions. In particular, Kirby, Doty, Petrocchi, and Gilbert (2017) have highlighted the importance of HRV in evaluating compassion-based interventions by suggesting that compassionate and self-compassionate interventions contribute to overall psychological and physiological wellbeing mainly by changes in HRV. The authors claim that field of compassion science needs to move toward including HRV as a primary outcome measure in its future assessment and training, due to its connection to vagal regulatory activity, and its link to overall health and wellbeing (Kirby, Doty, Petrocchi, \& Gilbert, 2017, p. 1). Since self-compassion interventions may generate a change in HRV, it is possible that self-compassion interventions are useful for increasing both psychological and physiological well-being.

This recommendation is supported by research which has demonstrated that self-compassion is related to higher HRV and lower negative affect in a stressful situation (Luo, Quiao, \& Che, 2018; Svendsen et al., 2016) and that mindfulness, which is a component of self-compassion, improves HRV, attentional control, and reduces worrying (Zwan, Wente, Huizink, \& Bruin, 2017). Rockliff, Gilbert, and McEwan (2008) examined the impact of compassion training on changes in HRV and cortisol levels. The results of the study indicated that individuals who score high on self-compassion and who responded to compassionate stimuli experienced a reduction in cortisol levels and an increase in HRV suggesting that the training had a soothing effect. Similarly, Matos et al. (2017), who studied the effect of a 14-day compassion-based intervention found that the intervention group showed an increase in HRV compared to the control group. Findings of Arch et al. (2014) revealed that the ability to be self-compassionate in a stressful situation was accompanied by a suppression of sympathetic activity, an increase in parasympathetic activity, and increase in HRV. For example, Stellar, Cohen, Oveis, and Keltner (2015) showed that the compassionate group experienced an increase in slow heart rate compared to three groups where compassion was not stimulated. Also, Stellar, Feinberg and Keltner (2014) found that the absence of compassion was characterized by physiological responses that diverged from patterns associated with compassion and social engagement (slower heart rate). These findings, therefore, concluded that the ability to be self-compassionate in a stressful situation is adaptive.

Generally, lower HRV is associated with self-criticism, anxiety, and depression (Kirby et al., 2017) but how individuals respond to imagery (as measured by physiological assessment [HRV]) also depends on their level of self-criticism (Rockliff et al., 2008). Although compassionate imagery stimulates the calming system in people with higher levels of self-compassion and potentially increase HRV, those who are self-critical may require therapeutic interventions before they can experience the benefits of compassion-based imagery. In summary, evidence suggests that interventions designed to promote self-compassion may increase self-reported assessments of self-compassion and a reduction in self-criticism but also manifest its effectiveness in increased HRV during guided imagery tasks.

\section{Aims}

The aim of the present study was to evaluate the effect of a 12-week group-based version of EFT-SCP program on HRV (as a physiological measure of health) during a guided imagery task and self-reported psychological outcomes (self-compassion, self-criticism and self-reassurance) in a student sample.

\section{Methods}

\section{Participants}

As studies suggest, young people tend to be more selfcritical (O'Connor \& Noyce, 2008) and thus they may be an appropriate sample to test the effect of the intervention aimed to increase self-compasion and decrease self-criticism. Therefore, this study will test the effectiveness of EFT-SCP with young adults attending University. A quasiexperimental design using cluster randomisation was adopted to recruit students undertaking a course in Psychology at a Comenius University in Slovakia. The participants 
were allocated to conditions by clustering groups based on their year of study. All participants received course credits for their participation. To minimise participants from discussing the study, the intervention was allocated to students in their fourth year of study, whilst the active control were in their second year of study and the no-treatment group were either in their first, third or fifth year of study. There were no important differences in the contexts for all students (e.g. exam stress) because the research study was delivered during winter semester. A total of 89 participants completed the pre-intervention measures and from this sample, 23 were allocated to the intervention group, 27 were assigned to the active control condition and 39 to the no-treatment control condition (see study attrition informa- tion in Figure 1). From this sample, 21 participants from the intervention group, 27 from the active control and 39 from the no-treatment group completed the post-intervention measures. Two participants from the intervention group dropped out of the study after group allocation. Two participants from the intervention group and 12 participants from the control groups were excluded due to errors in HRV measurement resulting in a final sample of 73 participants of which 19 were allocated to the intervention group, 20 in the active control group and 34 in the no-treatment control group. The final active control group consisted of 18 women and 2 men with a mean age of 20.35 years (standard deviation, $S D=1.45$ ), the final no-treatment control group consisted of 32 women and 2 men with a mean age

$N=208$

Eligible to participate
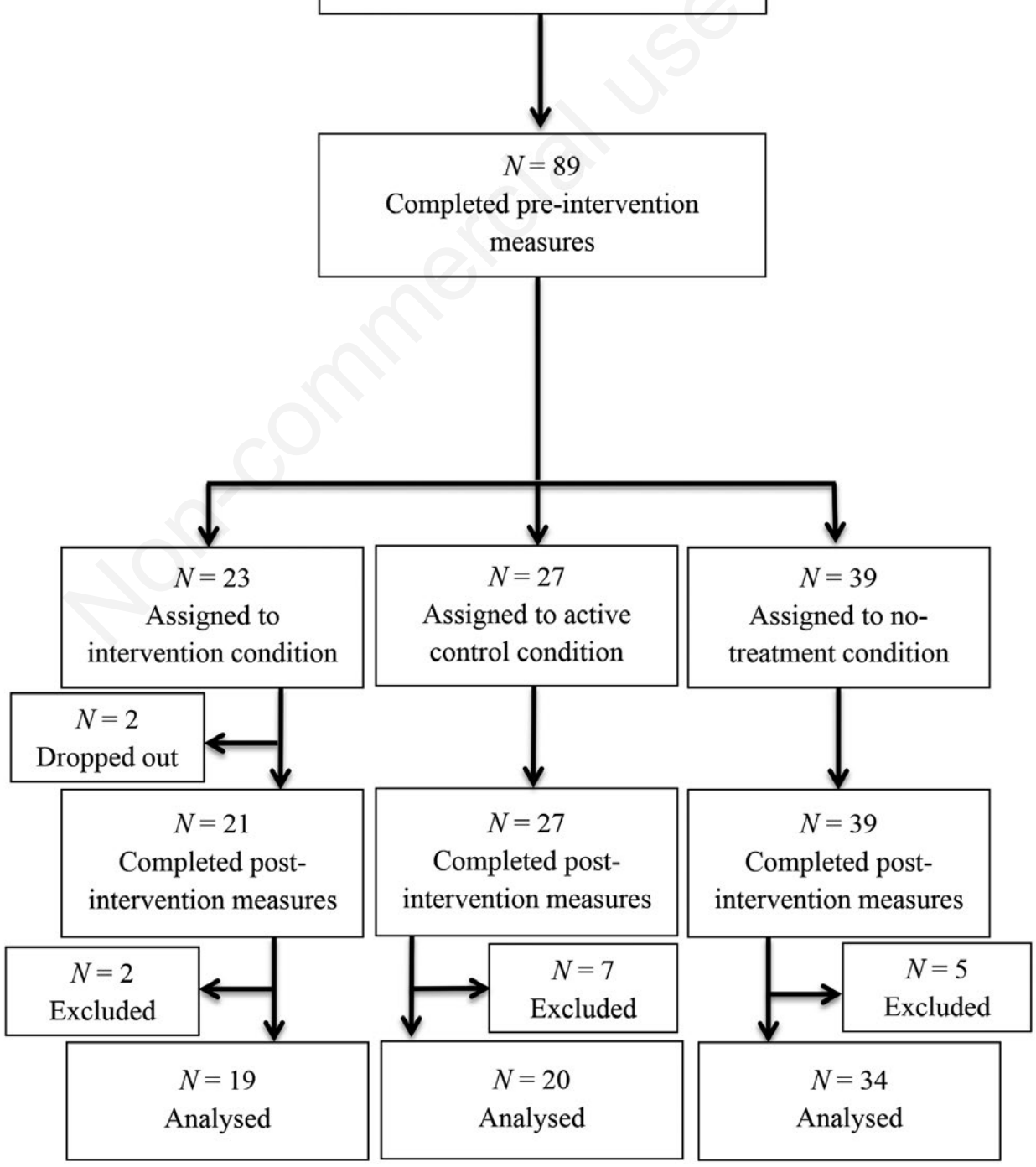

Figure 1. Flow chart for the number of participants who completed each phase of the study and attrition. 
of 21.81 years $(S D=1.56)$, and the intervention group consisted of 17 women and 2 men with mean age of 21.26 years $(S D=1.79)$.

\section{Procedure}

The data collected was in accordance with the ethical standards of the institutional research committee and with the 1964 Helsinki declaration and its later amendments or comparable ethical standards. All participants attended as assessment session in the laboratory where they provided informed consent and socio-demographic information. All participants were then instructed that their heart rate would be assessed during a guided imagery task (more information on the tasks provided below). During the guided imagery task HRV was measured by attaching disposable $\mathrm{Ag} / \mathrm{AgCl}$ electrodes from BIOPAC MP36 ((BIOPAC Systems, Inc., 42 Aero Camino Goleta, CA 93117, California, USA) to the person's ankles and right wrist while the person was in the sitting position. Electrodes were applied directly onto the skin and checked to ensure they were placed properly and firmly. ECG signal from $\mathrm{Ag} / \mathrm{AgCl}$ electrodes to BIOPAC hardware was transmitted by a shielded lead set SS2LB with standard pinch connectors. The signal that was obtained was verified by calibration and based on previous research we assessed ultra short HRV for 30 seconds (Salahuddin, Cho, Jeong, \& Kim, 2007) for the relaxation task and the guided imagery tasks. Each participant was instructed to remain in their seat with minimal movement and not to speak during ECG monitoring to stop the effects of movement on the results.

Following the relaxation and guided imagery tasks all participants completed an online survey measuring their levels of self-criticism and self-compassion. Participants who were allocated to the no-treatment control group were advised that they did not have to complete any other tasks until they receive an email to book an assessment day to complete the self-report measures and the HRV assessment. The active control group were instructed to write emotionally without worrying about grammer once a week about any experi ence they have that particular week. Participants were instructued that once a week they would receive a link to the online task where they would be able to complete the writing task. The intervention group were then provided with information on the 12-week course of Emotion Focused Training for Self-Compassion and Self-Protection. After 12 weeks, all participants were sent an email to book an assessment day to complete the self-report measures and the guided imagery task together with the HRV assessment.

\section{Guided imagery task}

The guided imagery task was completed twice 12weeks apart. Overall the task took 10 minutes to complete and to standardise the task, all participants were provided the instructions in the same order from a pre-recorded audiotape at both timepoints. The imagery task was provided in a lab with a research assistant who attached the eletrodes as described above and swiched on the recording. The tasks were designed to elicit relaxation, self-criticism, self-protection and self-compassion. Following each instruction, participants were given 30 seconds to complete the task. The imagery began with a relaxation instruction which involved closing their eyes and concentrating on breathing and relaxing their muscles. This was followed by instructions of guided imagery designed to trigger feelings of selfcriticism. The instructions were to remember a recent situation when they felt uncomfortable because of their own criticism, to imagine the part of them that criticised or attacked and to think about how they reacted to this experience of self-criticism. The second task involved eliciting feelings of self-protection. Participants were instructed to imagine the part of them which would want to defend them against their inner critic when experiencing feelings of failure and what they did to protect themselves. The final task involved elicting feelings of self-compassion which involved imagining their self-compassionate part that is loving, accepting and supportive at times of difficulty and they were encouraged to imagine how they would respond to their own self-compassion.

\section{Emotion focused training for self-compassion and self-protection}

The EFT-SCP intervention involved 1.5 hours a week of group training at the university and a daily EFT-SCP task for 12 weeks. All participants in the intervention group received a daily email with the task they needed to complete for that day. The task was the same for every day that week and it was associated with what had been discussed in the session that week. The e-mail describing the task was sent each day of the week except for the day of the course. Upon completing each task, participants were also instructed to provide feedback and a reflection of their experience (adherence check). Feedback was provided in the form of an online document. The additional function of the task and follow-up questions were to check and ensure that the participants completed the appropriate task. If the participant had not completed the exercise, they were sent an email reminder.

The tasks were a combination of exercises created for the purpose of this intervention and selected from a range of exercises related to self-compassion and self-criticism (e.g., Berg, 2012; Gilbert, 2009, 2010b; Germer, 2016; Germer \& Neff, 2013; Greenberg \& Warwar, 2006; Halamová, 2013; Neff, 2017; Rockman \& Hurley, 2015). Each exercise was created or selected and adapted by the first author and then discussed and approved by consensus by the research team. The criteria for each task was that it must capture the core elements of the EFT which include a process of change and the expected impact on self-com- 
passion and self-criticism, and participants' motivation to adhere to task instructions. All daily exercises were presented in the form of expressive writing. As a standalone therapeutic intervention, expressive writing has been shown to have a beneficial effect on a range of social, behavioural, psychological and health outcomes (e.g. Frattaroli, 2006). The content of the EFT-SCP training was as follows.

\section{Session 1}

Session 1 included an introduction to self-compassion and self-criticism during which participants shared their experiences of compassion. This was designed to elicit a definition of compassion based on experience. The group exercise involved discussing the task How would you treat a friend? (Gilbert, 2010b, p. 48; Neff, 2017; Rockman \& Hurley, 2015, p. 5). This task was designed to evoke insight into the different approaches people commonly use when treating friends and themselves in adverse situations. At the end of the session, participants were instructed that the daily task for the following week was Pleasurable everyday activities. They were instructed to complete this task mindfully by focusing their senses on the here and now. They were instructed that they could do this by concentrating on an activity or experience that occurred on that day and by doing this, to take pleasure from the activity. Participants were given examples of simple everyday activities which included walking, eating, driving and listening to music.

\section{Session 2}

Session 2 involved Compassionate calming down. The exercises for this session included Self-compassionate breathing, Self-compassionate body scan and Imagination of safe place (Gilbert, 2010b; Greenberg \& Warwar, 2006; Halamová, 2013; Luber, 2009; Rockman \& Hurley, 2015). The daily task for the following week was to practice calmness daily by using one of the exercises from the session.

\section{Session 3}

Session 3 was Leaving a painful past. This session consisted of exercises such as Leaving past relationships, Leaving anger and Forgiving yourself and others (Greenberg \& Warwar, 2006; Halamová, 2013; Rockman \& Hurley, 2015). The daily task for the following week was Letting go of a painful memory from your childhood (Halamová, 2013, p. 69). This task included writing a letter from the perspective of yourself as a child expressing pain, followed by responding to the letter from the child by writing a letter from the perspective as an adult. This task was designed to express compassion and protective anger towards themselves as a child. Participants were instructed to continue this task by writing letters between themselves as a child and as the adult with a final letter from the adult perspective responding to the child's needs (Halamová, 2013, p. 69).

\section{Session 4}

Session 4 addressed self-criticism with exercises of How self-critical/self-compassionate are you? (Neff, 2004), Imagining one's own self-critical part (awareness of its form and intensity as well as the impact it has on the self - Gilbert, 2010b), and Emotional drawing of own self-critic. The daily task for the week was Changing your self-critical dialogue (Neff, 2017).

\section{Session 5}

Session 5 was the first of two sessions on self-protection. The exercises during the group session were $A s-$ sertive rights (Smith, 1975), Saying no assertively, and Saying no empathically (Praško \& Prašková, 2007). Participants were instructed to use what they learnt in the session in their daily life by saying no to requests.

\section{Session 6}

Session 6 was the second part to self-protection. This session involved Expressing protective anger (Berg, 2012; Greenberg \& Warwar, 2006; Halamová, 2013). This task involved recalling an event when someone was critical towards you or shaming you and to imagine how your close friend would defend or protect you. Participants were instructed to reformulate the same protective response from the perspective of the friend to the self. This task was designed to enable participants to express their protective anger. The session also comprised of Self-protective dialogue training, Finding your self-protective voice, and Training of giving negative feedback (Halamová, 2013). The instruction for the daily task was to practice using self-protective language.

\section{Session 7}

Session 7 addressed the self-compassionate part of self. The exercises that were completed in this session were Compassion Flowing into you from others: using memory, Labeling emotions, Soften, soothe, allow, Selfcompassionate touch and Self-compassionate break (Gilbert, 2010b; Neff, 2017; Rockman \& Hurley, 2015). The daily task for the following week was Self-compassionate mirror. This task required participants to look in the mirror at the end of each day and be self-compassionate about pleasant or unpleasant events which may have occurred during the day followed by an expressive writing task to write about this experience (adapted from Petrocchi, Ottaviani, \& Couyoumdjian, 2017).

\section{Session 8}

Session 8 addressed the self-compassionate part of self. The exercises included Expressing compassion, Compassionate friend, Self-compassionate dialogue, 
Compassionate letter to myself, and Finding own selfcompassionate voice (Berg, 2012; Gilbert, 2010b; Halamová, 2013; Rockman \& Hurley, 2015). Participants were instructed to keep a daily diary of their bodily sensations, emotions, thoughts and behaviours and practised how to turn them into self-compassionate ones.

\section{Session 9}

Session 9 involved training communication between the three parts of the self: self-critical, self-protective and self-compassionate. To do this, participants completed an exercise adapted from Emotion Focused Therapy which is referred to as the Two chair dialogue. This excerise involves a dialogue between the criticizer and the criticized and the protective and the compassionate parts. The task Self-compassion in daily life (Germer, 2016) was selected as it encouraged participants to identify new ways to be more self-compassionate on physical, emotional, rational, social, and spiritual levels. Participants were instructed to practice the new selfcompassionate ways they identified during the group session and to write about their experience of using these new approaches.

\section{Session 10}

Session 10 was to develop ideal self-compassionate (Gilbert, 2010b) and self-protective images. This task involved imagining self-compassionate and self-protective ideal images and drawing them. The daily task was to practice responding to daily self-criticism using their selfcompasionate and self-protective ideal images developed during the group session.

\section{Session 11}

Session 11 was designed to help participants find their Specific types of self-critic. This involved working with own worries, anxiety, shame, and Identifying what I really want (Gilbert, 2010b; Neff, 2017; Rockman \& Hurley, 2015). The daily task was Searching for the benefits of self-critic. The task was to ask your own critic what it wishes to tell you, how it wants to take care of you, what it wants to protect you from and what are the different, more pleasant and compassionate ways of protection or motivation of self.

\section{Session 12}

Session 12 was the final session and conclusion of the training. The final exercises during the group session were Giving feedback on the training, Secret mails to everybody, and Appreciation of self which involved writing a comprehensive list of the things that you appreciate about yourself. The final daily task was Thanksgiving (Germer \& Neff, 2013; Gilbert, 2010b; Rockman \& Hurley, 2015). This was a daily task of writing a list of the things in your life you are thankful for or grateful about.

\section{Measures}

\section{Psychophysiological measure}

\section{Heart rate variability}

$\mathrm{HRV}$ is a measure of beat-to-beat fluctuations in heart rate and quantifies cardiac parasympathetic nervous system activity (Acharya, Joseph, Kannathal, Lim, \& Suri, 2006). There are various time-domain and frequency-domain measures of HRV, but only some of them perform satisfactorily for ultra-short ECG recordings (30 s) (Baek, Cho, Cho, \& Woo, 2015; Munoz et al., 2015; Nussinovitch et al., 2011): the Standard Deviation of the normal-to normal intervals (SDNN), the Root Mean Square of Successive Differences (RMSSD) between adjacent NNs and the median of the absolute differences of RR. For the purpose of this study we selected RMSSD as a measure of HRV because it is used to estimate the shortterm component of HRV (Malik et al., 1996) and a recent review of self-compassion intervention studies found that this is one of the most frequently used measure (Kirby et al., 2017).

\section{Self-report measures}

The Forms of Self-Criticising/Attacking and Self-Reassuring Scale

The FSCRS (Gilbert et al., 2004) is a 22 -item self-report measure comprising three subscales: Reassured-self (RS), Inadequate-self (IS), and Hated-self (HS). Participants are instructed to rate a selection of positive and negative statements on a 5-point Likert scale (Not at all like $m e$ to Extremely like me). Positive items reflect the ability to self-reassure (referred to as reassured-self) and negative items indicate self-critical thoughts and feelings (split into subscales of inadequate-self and hated-self). The psychometric properties and factor structure of this scale have been validated in 13 different nonclinical samples across 12 countries (Halamová et al., 2018). Cronbach's alpha for the current study were $0.81,0.88$ and 0.73 for Inadequate-Self, Reassured-Self and Hated-Self, respectively.

\section{Self-Compassion Scale}

Self-compassion was assessed using the Self-Compassion Scale (SCS; Neff, 2003) which measures six components of self-compassion experienced during perceived difficulty. The scale consists of 26 items rated on a 5-point Likert-type scale ( $1=$ almost never; $5=$ almost always). The scale consists of six subscales that measure the degree to which individuals display self-kindness against self-judgment, common humanity $v s$ isolation, and mindfulness $v s$ over-identification. A number of recent studies demonstrated that negative and positive subscales of SCS should be calculated separately and should not be summed as a single score (e.g., Brenner, Heath, Vogel, \& Credé, 2017; López et al., 2015). Therefore, for the purpose of this study, the combined score of the positive (self-compas- 
sionate responding: self-kindness, humanity and mindfulness) and negative (self-uncompassionate responding: self-judgement, isolation and over-identification) constructs will be used. Cronbach's alpha for the current study were 0.82 and 0.86 for Self-uncompassionate responding nd Self-compassionate responding, respectively.

\section{Data analysis}

For the statistical data analyses, we used the program R (Version 3.4.0, R Core Team, 2013), the library RHRV (Rodriguez-Linares et al., 2011), and the library nparLD (Noguchi, Gel, Brunner, \& Konietsche, 2012). At first, we tested normal distribution of the related variables (imagery tasks, pre and post-measurements and participants in control or intervention groups). Many classical nonparametric alternatives (Wilcoxon-Mann-Whitney test, Kruskal-Wallis test, Wald-type statistics) perform poorly for small sample sizes, heteroscedasticity and unbalanced designs (when the sample sizes of the control and intervention groups differ; see Brunner, Domhof, \& Langer, 2002; Brunner, Konietschke, Pauly, \& Puri, 2017; Brunner, Munzel, \& Puri, 1999). Moreover, our intervention design practically excludes equal variances of control and intervention groups. Therefore, our data are heteroscedastic, thus the intervention group usually decreases variance in its group due to ceiling effect: if the intervention is effective only for some participants, variance in posttest group could be substantially lower. There are well-justified statistical reasons to use nonparametric heteroscedastic methods for our statistical analyses. We report ANOVA-type statistics (Brunner et al., 2017) from nonparametric rank-based test for longitudinal data, and relative effects which can serve as effect size measures (for relative effects as effect sizes, see Grissom \& Kim, 2012, chap. 6). The relative effect can be regarded as the probability that a randomly chosen observation from the intervention group takes on larger values than an observation randomly chosen from the mean distribution function. Therefore, a relative effect significantly higher (for increasing effect) or lower (for decreasing effect) than .50 indicates that an intervention was effective. ANOVA-type statistics perform well even for small sample sizes and unbalanced designs (Brunner et al., 2002). In most cases when a split-plot design with repeated measures is conducted, it is mainly of interest to investigate an interaction between groups (factor $\mathrm{G}$ ) and time (factor T). In our split-plot design, there are control groups which did not undertake the intervention of interest (groups 1 and 2) and the active treatment is given to the intervention group (group 3), therefore the distribution functions at the start of the trial (pre-test) are identical because the participants were cluster randomised to the two groups of factor G. Then, an effect of the active intervention should produce nonparallel time curves of the measurements. This means that there should be a significant interaction between factor $\mathrm{G}$ and factor $\mathrm{T}$ if the intervention is effective. We hy- pothesize that our intervention will be significantly effective if and only if the interaction between groups (control vs intervention) and time (two time points, pre- and posttest) is significant: therefore, the significant difference between active control, no-treatment control and intervention group or between time points alone will not do. Main factorial effects (difference between groups regardless of time, or difference among time points regardless of groups) are of no use here, so we will not report them. Data-analyses methods were decided before the data were gathered, and they were selected because these statistical methods were recently developed for non-parametric analysis of longitudinal data in parallel and factorial experiments with small sample sizes and unbalanced designs (Erceg-Hurn \& Mirosevich, 2008).

\section{Results}

In sum, we used 24 variables: 4 tasks (Baseline/Relaxation, Self-Criticism, Self-Protection, and Self-Compassion), each task had pre-test and post-test measurement (repeated-measures, dependent groups), and participants were allocated either to the intervention, active control or non-treatment control group. Out of 24 variables, only 2 displayed normal distribution (all Shapiro-Wilk tests except 2 had $\mathrm{P}<.001$ ). In all variables, 3 to 14 outlying values were detected. We report descriptive statistics for HRV scores for the relaation and guided imagery tasks in Appendix Table A1.

Kruskal-Wallis test confirmed that no between-group differences were present at baseline, $\chi^{2}(2)=0.151, \mathrm{P}=.927$ or for each of the guided imargery tasks (self-criticism, $\chi^{2}(2)=0.167, \mathrm{P}=.920$, self-protection, $\chi^{2}(2)=0.001, \mathrm{P}=.999$, and self-compassion, $\chi^{2}(2)=0.452, \mathrm{P}=.798$ ).

Following nonparametric analyses to test for interaction effects, factor $\mathrm{G}$ (difference between active control, no-treatment control, and intervention group) should significantly interact with factor $\mathrm{T}$ (difference between preand post-test) implying that only the intervention group should change on post-test. In Table 1 and Appendix Tables A1, we report the descriptive statistics for the HRV scores for the relaxation task and the guided imagery tasks and the Anova-type statistics for this interaction effect, and its relative treatment effects as effect sizes, respectively. Table 1 demonstrates that there was no significant interaction in the baseline relaxation task. However, there was significant interaction in the Self-Criticism and the Self-Compassion tasks but no significant interaction in the Self-Protection task.

These findings are also represented in Figure 2 (RMSSD variable for the Self-Criticism task), which shows that there was significant interaction between the control groups and intervention group: the intervention group is clearly different to the control groups on posttest follow-up. In Figure 3 (RMSSD variable for the SelfProtection task), although there is a change, it is not 
significant. In Figure 4 (RMSSD variable for the SelfCompassion task), there is significant interaction between the control groups and intervention group.

We also tested the changes in self-report measures of self-criticism/reassurance (FSCRS) and self-compassion (SCS). Table 2 and Appendix Table A2 present the results of the descriptive statistics and Anova-type statistics, respectively. We used three sum scores from the
FSCRS (Inadequate-Self, Reassured-Self, Hated-Self) and two sum scores from the SCS (Self-Compassionate Responding and Self-Uncompassionate Responding). The intervention was effective in decreasing levels of Inadequate-Self, Hated-Self and Self-Uncompassionate Responding. However, the intervention was not effective in increasing Reassured-Self and Self-Compassionate Responding.

Table 1. Results of the repeated measures Anova-type statistics and relative effects comparing the three groups on mean Root Mean Square of Successive Differences pre- and post-test scores (assessment of heart rate variability).

\begin{tabular}{|c|c|c|c|c|c|}
\hline \multirow{2}{*}{ Task } & \multicolumn{3}{|c|}{ ATS } & \multicolumn{2}{|c|}{ RTE } \\
\hline & $F$ & $d f$ & $\mathbf{P}$ & Pre-test & Post-test \\
\hline \multirow[t]{3}{*}{ Baseline group: time } & 0.39 & $1.80, \infty$ & $=.652$ & Non-Tx control .51 & Non-Tx control .50 \\
\hline & & & & Active control .48 & Active control .52 \\
\hline & & & & Intervention .48 & Intervention .51 \\
\hline \multirow[t]{3}{*}{ Self-Criticism group: time } & 3.03 & $1.97, \infty$ & $<.049 *$ & Non-Tx control .47 & Non-Tx control .46 \\
\hline & & & & Active control .50 & Active control .52 \\
\hline & & & & Intervention .47 & Intervention $.63^{*}$ \\
\hline \multirow[t]{3}{*}{ Self-Protection group: time } & 0.53 & $1.90, \infty$ & $=.577$ & Non-Tx control .52 & Non-Tx control .48 \\
\hline & & & & Active control .52 & Active control .52 \\
\hline & & & & Intervention .52 & Intervention .47 \\
\hline \multirow[t]{3}{*}{ Self-Compassion group: time } & 5.17 & $1.92, \infty$ & $<.007 * *$ & Non-Tx control .46 & Non-Tx control .47 \\
\hline & & & & Active control .51 & Active control .52 \\
\hline & & & & Intervention .48 & Intervention $.62 *$ \\
\hline
\end{tabular}

Bold, significant value; ATS, Anova-type statistics; RTE, relative effects. Non-Tx Control, no-treatment control group; Active control, active control group; Time, pre-pretest or post-posttest. *Significant at 0.05 level; **Significant at 0.01 level; ***Significant at 0.001 level.

\section{Relative Effects}

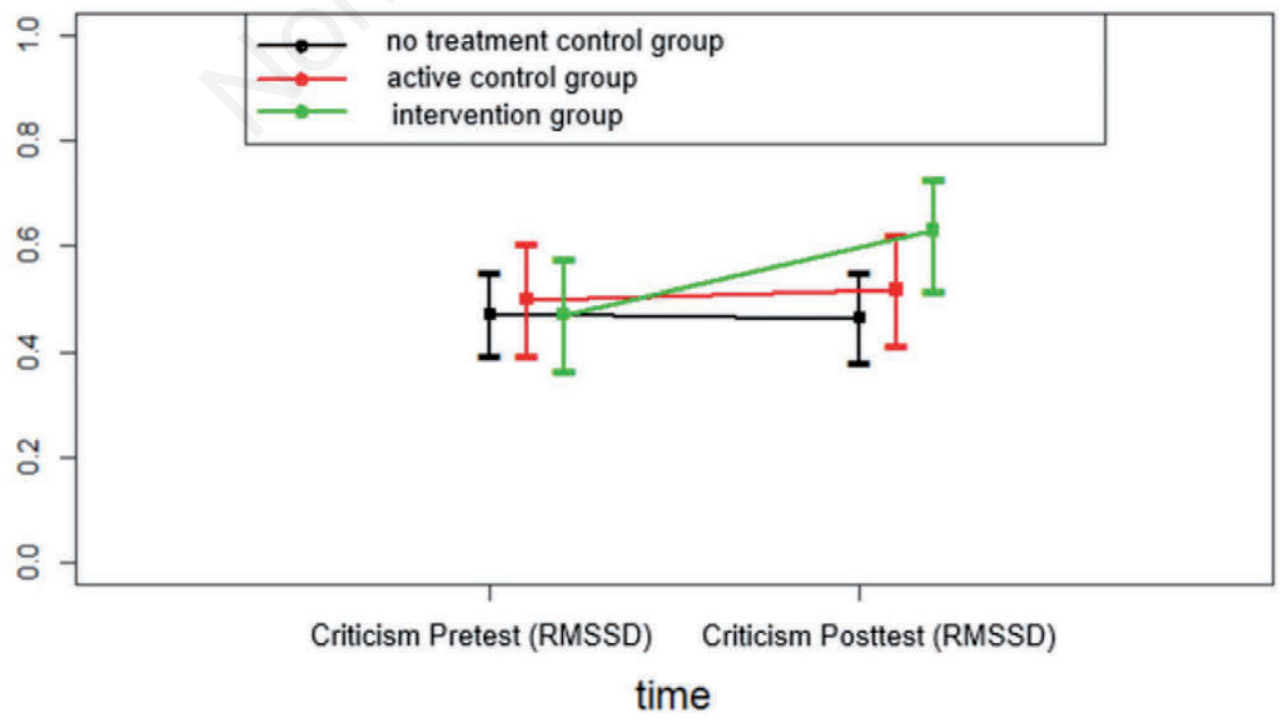

Figure 2. Difference in Root Mean Square of Successive Differences (RMSSD) scores between groups for the Self-Criticism Imagery task. 


\section{Discussion}

The present study examined the psychological and physiological effects of a 12-week group-based version of EFT-SCP program on self-compassion (self-compassionate responding and self-uncompassionate responding of SCS), self-criticism and self-reassurance (FSCRS), and HRV during guided imagery tasks eliciting self-criticism, self-compassion and self-protection in a student population.

The findings demonstrated that compared to the two control groups, the EFT-SCP intervention group showed significant increases in HRV during guided imagery tasks

Table 2. Results of the repeated measures Anova-type statistics and relative effects comparing the three groups on mean Forms of Self-Criticism/Reassuring Scale and Self-Compassion Scale subscale scores pre- and post-test scores.

\begin{tabular}{|c|c|c|c|c|c|}
\hline \multirow[t]{2}{*}{ Subscale } & \multicolumn{3}{|c|}{ ATS } & \multicolumn{2}{|c|}{ RTE } \\
\hline & $\boldsymbol{F}$ & $d f$ & $\mathbf{P}$ & Pre-test & Post-test \\
\hline \multirow[t]{3}{*}{ FSCRS inadequate-self group: time } & 4.16 & $1.95, \infty$ & $<.017 *$ & Non-Tx control .55 & Non-Tx control .53 \\
\hline & & & & Active control .53 & Active control .51 \\
\hline & & & & Intervention .50 & Intervention $.34^{*}$ \\
\hline \multirow[t]{3}{*}{ FSCRS reassured-self group: time } & 1.81 & $1.85, \infty$ & $=.166$ & Non-Tx control .51 & Non-Tx control .52 \\
\hline & & & & Active control .52 & Active control .53 \\
\hline & & & & Intervention .51 & Intervention .53 \\
\hline \multirow[t]{3}{*}{ FSCRS hated-self group: time } & 12.41 & $1.82, \infty$ & $<.001 * * *$ & Non-Tx control .52 & Non-Tx control .52 \\
\hline & & & & Active control .55 & Active control .51 \\
\hline & & & & Intervention .55 & Intervention $.33 * *$ \\
\hline \multirow[t]{3}{*}{ SCS compassionate-responding group: time } & 1.32 & $1.82, \infty$ & $=.267$ & Non-Tx control .49 & Non-Tx control .49 \\
\hline & & & & Active control .44 & Active control .43 \\
\hline & & & & Intervention .53 & Intervention .54 \\
\hline \multirow[t]{3}{*}{ SCS uncompassionate-responding group: time } & 10.14 & $1.96, \infty$ & $<.001 * * *$ & Non-Tx control .55 & Non-Tx control .54 \\
\hline & & & & Active control .51 & Active control .52 \\
\hline & & & & Intervention .52 & Intervention $.39 *$ \\
\hline
\end{tabular}

Bold, significant value; ATS, Anova-type statistics; RTE, relative effects; FSCRS, Forms of Self-Criticism/Reassuring Scale; SCS, Self-Compassion Scale; Non-Tx Control, no-treatment control; Active control, active control group. *Significant at 0.05 level; **Significant at 0.01 level; ***Significant at 0.001 level.

\section{Relative Effects}

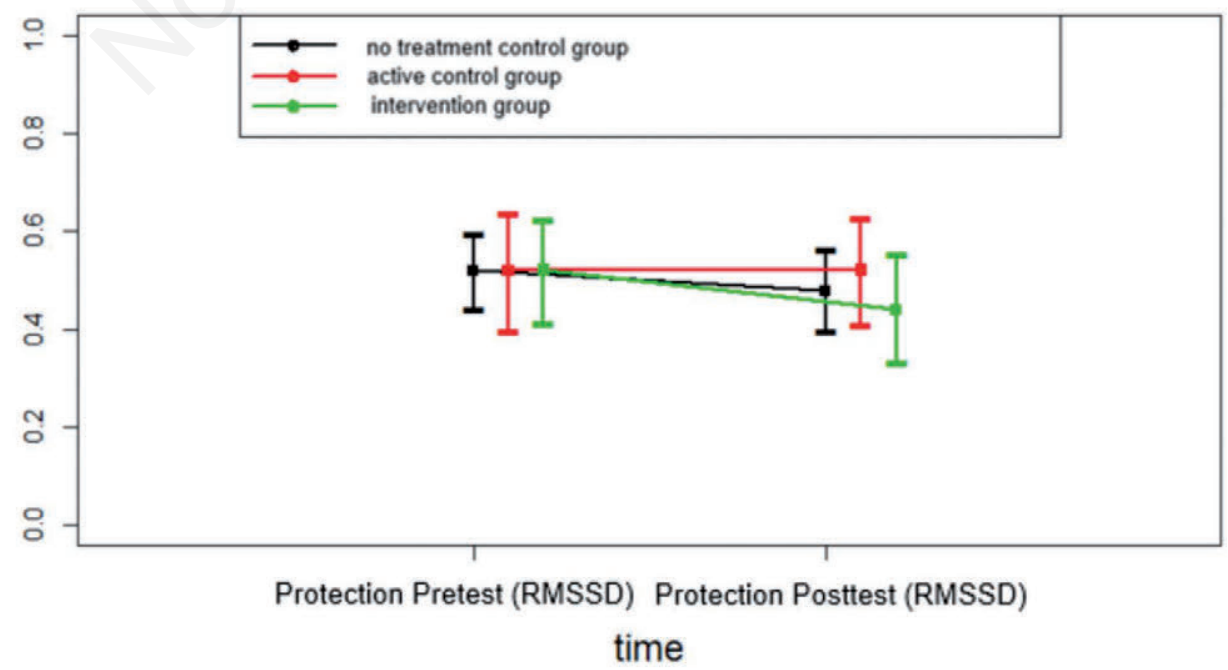

Figure 3. Difference in Root Mean Square of Successive Differences (RMSSD) scores between groups for the Self-Protection Imagery task. 
of self-compassion and self-criticism. This suggests that addressing self-criticism reduced perceptions of self-criticism and increased self-reports of self-compassion and was found to increase HRV. The increase in HRV suggests that the intervention was effective in activating the parasympatic nervous system, which may mediate the changes in self-criticism and self-compassion. Our research study did not show a significant interaction in HRV during the self-protective guided imagery task. During the training participants were taught to express protective anger and not reactive anger therefore, this could indicate that they did not need to physiologically display more anger or more arousal because they learnt to set boundaries and be assertive with their self-criticisim.

Participation in group training and performing exercises to improve the skills of self-compassion and protective anger for three months were found to improve self-criticism but not self-compassion. Specifically, the findings suggest that the EFT-SCP has an effect on Selfuncompassionate responding, and Self-criticism (Hatedand Inadequate-self) as measured by the SCS (Neff, 2003) and FSCRS (Gilbert et al., 2004), respectively. However, the EFT-SCP did not have an effect on Self-compassionate responding (SCS) and Reassured-Self (FSCRS). It is possible that this finding is is a result of the ceiling effect: many participants reported high scores at baseline, and therefore any treatment effect was limited. These findings are partly supported by a previous study which examined the effects of an online version of a short EFT-SCP course (Halamová, Kanovský, Varšová, \& Kupeli, 2018). This study demonstrated that a short online EFT-SCP led to improvements in both self-compassion and self-criticism with an effect lasting at least two months post-intervention
(Halamová et al., 2018). However, this study employed a community sample (Halamová et al., 2018) compared to the current study which recruited students studying psychology.

The EFT-SCP might have been effective in reducing self-criticism and self-uncompassionate responding through its teachings of self-compassion together with training individuals to set boundaries for their protective anger as a way of addressingt self-criticism. As previously mentioned, it may not be sufficient to learn to be compassionate towards one's own self-critic, but one must also be assertive and express protective anger against self-criticisim (Whelton \& Greenberg, 2005). Also, Kelly et al. (2008) recommended the combination of these two approaches. However, self-compassion and self-criticism seem to stem from distinct physiological systems and brain regions. Simon-Thomas et al. (2011) found, that compassion induction was connected to activation in the brain associated with experiences of pain in ourselves or others, while inducing competitive behavior was linked to regions of the brain associated with self-referent processing. Longe et al. (2010) demonstrated that being self-reassuring for low self-critical people activated brain regions responsible for calming, but in highly self-critical people it was exactly the opposite and regions associated to threat systems were activated. Rockliff et al. (2011) found, that oxytocin may provide many people with feelings of compassion and reassurance but it can also potentially have a negative impact on highly self-critical people. Gilbert (2015) highlights, that soothing and threatening systems influence one another and our prosocial competencies serve as a mediator to stabilize sense of self.

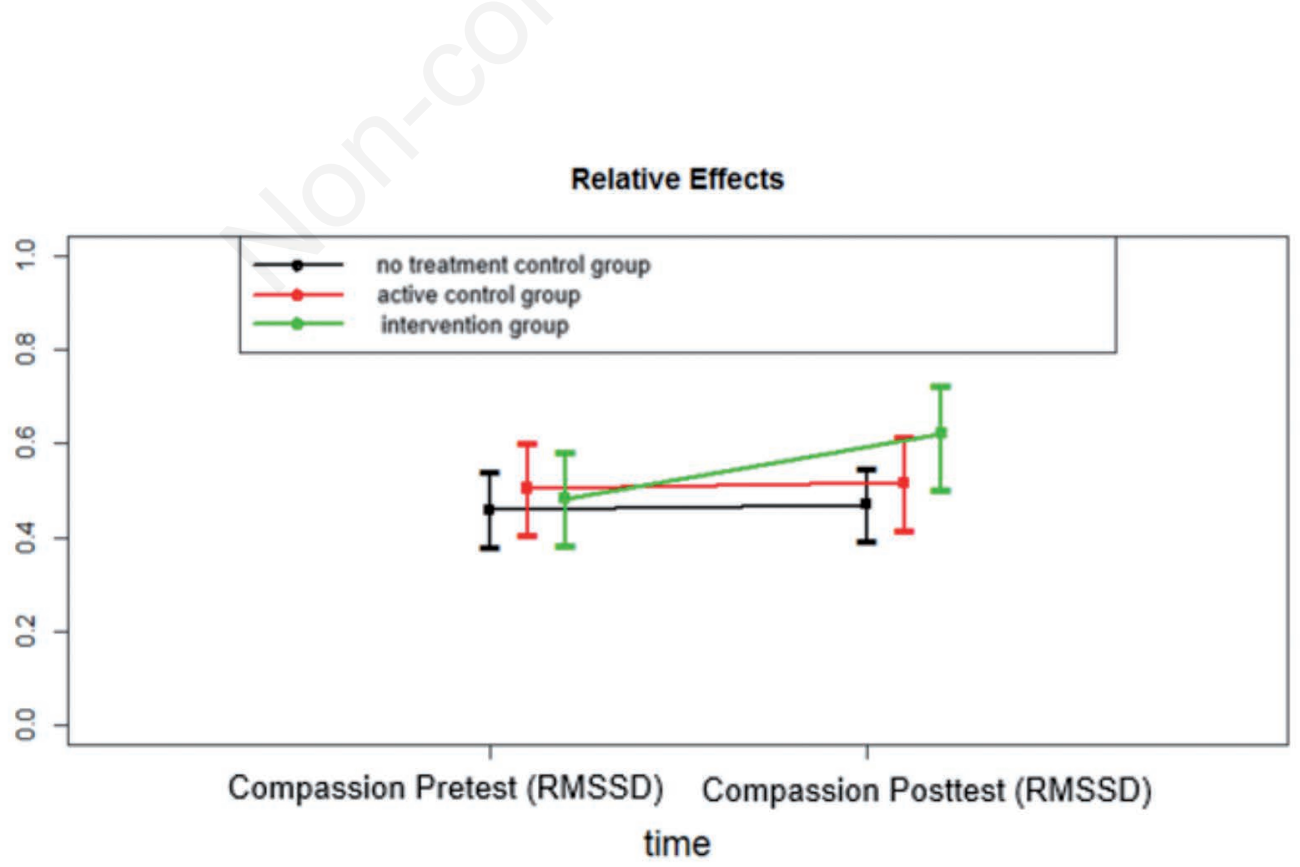

Figure 4. Difference in Root Mean Square of Successive Differences (RMSSD) scores between groups for the Self-Compassion Imagery task. 


\section{Strengths, limitations and future research}

Although the process of selecting or even designing a suitable control condition for psychotherapeutic interventions is particularly difficult (Safer \& Hugo, 2006), a strength of the current study is the use of two control conditions. In particular, the use of an active control condition which used the same method of expressive writing as the intervention but different enough to know that the positive effects of the intervention were a result of the intervention and not the process of writing itself.

Another strength of this study is the use of HRV which provided an objective assessment of the phenomena under study. Physiological indicators such as HRV are generally more reliable than self-report measures which may be subject to responder bias and social desirability. The use of HRV during imagery tasks in this study provided a more applicable approach to real life situations compared with self-rating scales which are susceptible to misinterpretation. However, it is important to add that we used validated and psychmetrically sound tools of self-criticism/reassurance and self-compassion. The improvement in self-compassion and reduction in self-criticism also demonstrate that whilst HRV provides an objective assessment of intervention efficacy, self-report tools used in this study are also appropriate methods for assessing the effects of an intervention.

However, this study also is not without its limitations and we recommend the findings are interpreted with these in mind. This study reported findings from a student sample f from one country, and thus these findings cannot be generalised to clinical samples or to different countries without further research. Another limitation of this study is that the number of men who took part in this study was considerally lower compared to the number of women who participated. Hence, further research on how men and women respond to EFT-SCP is required. Also, statistical power may have been limited due to the small sample sizes employed in each group. Although this study employed a treatment vs no-treatment and an active control design, where we found differences in HRV, it should be held in mind that HRV can be influenced by various endogenous and exogenous factors such as heritability (Singh, 1998), sex and age (Palantini, 1998). What is more relevant in our study is body posture (Pomeranz et al., 1985) or body temperature (Cooper, 1994) and therefore, a caveat of these findings is that the positive changes in HRV may be partially a result of confounding variables due to the measurement process. However, we minimised the effect of measurement confounders on HRV by ensuring that the physical environment and body posture of participants during assessments was the same.

A final limitation is that this study did not assess participant's ability to generate or engage in mental imagery which may contribute to how participants respond to interventions (Kelly, Zuroff, Foa, \& Gilbert, 2010). Although this study did not assess the ability to generate mental imagery, our results suggest that participants were engaged with the intervention to experience the positive effects of EFT-SCP. Particularly, in their phsyiological responses to recalling imagery of self-criticisim and selfcompassion.

\section{Conclusions}

A group-based EFT-SCP training has significantly increased HRV and decreased self-reported levels of selfuncompassionate responding and self-criticism (both Hated-self and Inadequate-Self as measured by the FSCRS) in a sample of students. These results are promising however; the mechanisms by which this intervention leads to improvements require further investigation.

\section{References}

Acharya, U. R., Joseph, K. P., Kannathal, N., Lim, C. M., \& Suri, J. S. (2006). Heart rate variability: a review. Medical and Biological Engineering and Computing, 44, 1031-1051. doi: 10.1007/s11517-006-0119-0

Akin, A. (2009). Self-compassion and submissive behavior. Education and Science, 34(152), 138-147.

Akselrod, S., Gordon, D., Ubel, F. A., Shannon, D. C., Barger, A. C., \& Cohen, R. J. (1981). Power spectrum analysis of heart rate fluctuation: a quantitative probe of beat-to-beat cardiovascular control. Science, 213, 220-222. doi: 10.1126/science.6166045

Arch, J. J., Warren Brown, K., Dean, D. J., Landy, L. N., Brown, K. D., \& Laudenslager, M. L. (2014). Self-compassion training modulates alpha amylase, heart rate variability, and subjective responses to social evaluative threat in women. Psychoneuroendoicronology, 42, 49-58. doi: 10.1016/j. psyneuen.2013.12.018

Baek, H. J., Cho, C.-H., Cho, J., \& Woo, J. M. (2015). Reliability of ultra-short-term analysis as a surrogate of standard 5-min analysis of heart rate variability. Telemedicine and e-Health, 21(5), 404-414. doi: 10.1089/tmj.2014.0104

Berg, R. (2012). Emotion focused therapy homework: decision tree, therapist instructions and client handouts. California: Rosemead School of Psychology, Biola University.

Blatt, S. J., \& Zuroff, D. C. (1992). Interpersonal relatedness and self-definition: Two prototypes for depression. Clinical Psychology Review, 12(5), 527-562. doi: 10.1016/02727358(92)90070-o

Bornemann, B., Kok, B. E., Bockler, A., \& Singer, T. (2016). Helping from the heartcour: Voluntary upregulation of heart rate variability predicts altruistic behavior. Biological Psychology, 119, 54-63. doi: 10.1016/j.biopsycho.2016.07.004

Borrione, L., Brunoni, A. R., Pereira, B. S., Aparicio, L. M., Kemp, A. H., Besenor, I., ... Fraguas, R. (2018). Associations between symptoms of depression and heart rate variability: An exploratory study. Psychiatry Research, 26(4), 482-487. doi: 10.1016/j.psychres.2017.09.028

Brenner, R. E., Heath, P. J., Vogel, D. L., \& Credé, M. (2017). Two is more valid than one: examining the factor structure of the Self-Compassion Scale (SCS). Journal of Counseling Psychology, 64(6), 696-707. doi: 10.1037/cou0000211 
Brunner, E., Domhof, S., \& Langer, F. (2002). Nonparametric analysis of longitudinal data in factorial designs. New York: Wiley.

Brunner, E., Konietschke, F., Pauly, M., \& Puri, M. L. (2017). Rank-based procedures in factorial designs: hypotheses about non-parametric treatment effects. Journal of the Royal Statistical Society B, 79(5), 1463-1485. doi: 10.1111/rssb. 12222

Brunner, E., Munzel, U., \& Puri, M. L. (1999). Rank-score tests in factorial designs with repeated measures. Journal of Multivariate Analysis, 70, 286-317. doi: 10.1006/jmva.1999. 1821

Cooper, K. E. (1994). Some responses of cardiovascular system to heat and fever. The Canadian Joural of Cardiology, 10(4), 444-448.

Elliott, R., Watson, J. C., Goldman, R. N., \& Greenberg, L. S. (2004). Learning emotion-focused therapy. Washington, D. C.: American Psychological Association Press.

Erceg-Hurn, D., \& Mirosevich, V. M. (2008). Modern robust statistical methods: An easy way to maximize the accuracy and power of your research. American Psychologist, 63(7), 591-601. doi: 10.1037/0003-066X.63.7.591

Frattaroli, J. (2006). Experimental disclosure and its moderators: A meta-analysis. Psychological Bulletin, 132(6), 823-865. doi: 10.1037/0033-2909.132.6.823

Germer, C. K. (2016). Self-compassion in daily life. Retrieved from: https://chrisgermer.com/wp-content/uploads/2017/01/ Self-Compassion-in-Daily-Life.pdf Accessed: October 2, 2016.

Germer, C. K., \& Neff, K. D. (2013). Self-compassion in clinical practice. Journal of Clinical Psychology, 69(8), 856-867. doi: $10.1002 /$ jclp.22021

Gilbert, P. (2009). The compassionate mind. London: Constable Robinson.

Gilbert, P. (2010a). Compassion focused therapy: Distinctive features. London: Routledge.

Gilbert, P. (2010b). Training our minds in, with and for compassion. An introduction to concepts and compassion-focused exercises. Retrieved from: http://wtm.thebreathproject.org/ wp-content/uploads/2016/03/COMPASSIONHANDOUT.pdf Accessed: August 21, 2016.

Gilbert, P. (2014). The origins and nature of compassion focused therapy. British Journal of Clinical Psychology, 53(1), 6-41. doi: $10.1111 /$ bjc. 12043

Gilbert, P. (2015). Affiliative and prosocial motives and emotions in mental health. Dialogues in Clinical Neuroscience, 17, 381-389.

Gilbert, P., \& Choden. (2013). Mindful compassion. London, UK: Constable-Robinson.

Gilbert, P., Clark, M., Hempel, S., Miles, J. N. V., \& Irons, C. (2004) Criticising and reassuring oneself: An exploration of forms, styles and reasons in female students. British Journal of Clinical Psychology, 43(1), 31-50. doi: 10.1348/ 014466504772812959

Gilbert, P., \& Irons, C. (2004). A pilot exploration of the use of compassionate images in a group of self-critical people. Memory, 12(4), 507-516. doi: 10.1080/096582104440 00115

Gilbert, P., \& Procter, S. (2006). Compassionate mind training for people with high shame and self-criticism: Overview and pilot study of a group therapy approach. Clinical Psychology and Psychotherapy, 13, 353-379. doi: 10.1002/cpp.507

Greenberg, L. S. (2011). Emotion-focused therapy. Theories of psychotherapy series. Washington, DC: American Psychological Association.

Greenberg, L. S., \& Warwar, S. H. (2006). Homework in an emotion-focused approach to experiential therapy. Journal of Psychotherapy Integration, 16(20), 178-200. doi: 10.1037/1053-0479.16.2.178

Greenberg, L. S., \& Watson, J. (2005). Emotion-focused therapy of depression. Washington, D. C.: American Psychological Association Press.

Grissom, R. J., \& Kim, J. J. (2012). Effect sizes for research. Univariate and multivariate applications. New York: Routledge.

Hackmann, A., \& Holmes, E. A. (2004). Reflecting on imagery: A clinical perspective and overview of the special issue of memory on mental imagery and memory in psychopathology. Memory, 12(4), 389-402. doi: 10.1080/ 09658210444000133.

Halamová, J. (2013). Terapia zameraná na emócie - cvičebnica. Bratislava: Komenského University.

Halamová, J., Kanovský, M., Gilbert, P., Kupeli, N., Troop, N., Zuroff, D., ... Basran, J. (2018). The factor structure of the Forms of Self-Criticising/Attacking \& Self-Reassuring Scale in thirteen populations. Journal of Psychopathology and Behavioral Assessment. Online First Publication. doi: 10.1007/s10862-018-9686-2

Halamová, J., Kanovský, M., Varšová, K., \& Kupeli, N. (2018). Randomised Controlled Trial of the New Short-Term Online Emotion Focused Training for Self-Compassion and SelfProtection Training in a Nonclinical Sample. Current psychology. Online First Publication. doi: 10.1007/s12144018-9933-4

Jackowska, M., Hamer, M., Carvalho, L. A., Erusalimsky, J. D., Butcher, L., \& Steptoe, A. (2012). Short sleep duration is associated with shorter telomere length in healthy men: findings from the Whitehall II cohort study. PloS One, 7(10), e47292. doi: 10.1371/journal.pone.0047292

Javorka, K. (2008). Variabilita frekvencie srdca. Mechanizmy, hodnotenie a klinické využitie. Martin: Osveta.

Kelly, A. C., Zuroff, D. C., Foa, C. L., \& Gilbert, P. (2010). Who benefits from training in self-compassionate self-regulation? A study of smoking reduction. Journal of Social and Clinical Psychology, 29(7), 727-755. doi: 10.1521/jscp.2010. 29.7.727

Kelly, A. C., Zuroff, D. C., \& Shapira, L. B. (2008). Soothing oneself and resisting self-attacks: The treatment of two intrapersonal deficits in depression vulnerability. Cognitive Therapy and Research, 33, 301-313. doi: 10.1007/s10608008-9202-1

Kemp, A. H., \& Quintana, D. S. (2013). The relationship between mental and physical health: insights from the study of heart rate variability. International Journal of Psychophysiology, 89(3), 288-296. doi: 10.1016/j.ijpsycho. 2013.06.018

Kirby, J. N. (2017). Compassion interventions: The programmes, the evidence, and implications for research and practice. Psychology and Psychotherapy: Theory, Research and Practice, 90(3), 432-455. doi: 10.1111/papt.12104

Kirby, J. N., Doty, J. R., Petrocchi, N., \& Gibert, P. (2017). The current and future role of heart rate variability for assessing and training compassion. Frontiers in Public Health, 5, 4048. doi: 10.3389/fpubh.2017.00040

Krygier, J. R., Heathers, J. A. J., Shahrestani, S., Abbott, M., Gross, J. J., \& Kemp, A. H. (2013). Mindfulness medita- 
tion, well-being, and heart rate variability: A preliminary investigation into the impact of intensive Vipassana meditation. International Journal of Psychophysiology, 89(3), 305-313.

Lang, P. J., Kozak, M. J., Miller, G. A., Levin, D. N., \& McLean, A. (1980). Emotional imagery: Conceptural structure and pattern of somato-visceral response. Psychophysiology, 17(2), 179-192. doi: 10.1111/j.1469-8986.1980.tb00133.x

Lehrer, P. M., \& Gevirtz, G. (2014). Heart rate variability biofeedback: how and why does it work? Frontiers in Psychology, 5, 1-9. doi: 10.3389/fpsyg.2014.00756

Leighton, T. D., \& Halifax, J. (2003). Faces of compassion: Classic bodhisattva archetypes and their modern expression. Somerville, MA: Wisdom Publication.

Longe, O., Maratos, F. A., Gilbert, P., Evans, G., Volker, F., Rockliff, H., \& Rippon, G. (2010). Having a word with your-self: Neural correlates of self-criticism and self-reassurance. Neuroimage, 49(2), 1849-1856. doi: 10.1016/j.neuroimage.2009.09.01

López, A., Sanderman, R., Smink, A., Zhang, Y., van Sonderen, E., Ranchor, A., \& Schroevers, M. J. (2015). A reconsideration of the Self-Compassion Scale's total score: self-compassion versus self-criticism. PloS One, 10(7). doi: 10.1371/journal.pone.0132940

Luber, M. (2009). Eye Movement Desensitization and Reprocessing (EMDR) scripted protocols: Basics and special situations. New York: Springer.

Luo, X., Qiao, L., \& Che, X. (2018). Self-compassion modulates heart rate variability and negative affect to experimentally induced stress. Mindfulness, 41(9), 1103-1113. doi: 10.1007/ s12671-016-0549-1

MacBeth, A., \& Gumley, A. (2012). Exploring compassion: A meta-analysis of the association between self-compassion and psychopathology. Clinical Psychology Review, 32(6), 545-552. doi: 10.1016/j.cpr.2012.06.003

Malik, M., Camm, A. J., Bigger, J. T., Breithardt, G., Cerutti, S., Cohen, R. J., ... Singer, D. H. (1996). Heart rate variability: Standards of measurement, physiological interpretation, and clinical use. European Heart Journal, 17(3), 354-381.

Marshall, S. L., Parker, P. D., Ciarrochi, J., Sahdra, B., Jackson, C. J., \& Heaven, P. C. (2015). Reprint of Self-compassion protects against negative effects of low self-esteem: A longitudinal study in a large adolescent sample. Personality and Individual Differences, 81, 201-206. doi: 10.1016/j.paid. 2014.09.049

Matos, M., Duarte, C., Duarte, J., Pinto-Gouveia, J., Petrocchi, N., Basran, J., \& Gilbert, P. (2017). Psychological and physiological effects of compassionate mind training: A pilot randomized controlled study. Mindfulness, 8(6), 1699-1712. doi: 10.1007/s12671-017-0745-7

Mayhew, S. L., \& Gilbert, P. (2008). Compassionate mind training with people who hear malevolent voices: A case series report. Clinical Psychology and Psychotherapy, 15, 113138. doi: $10.1002 /$ cpp.566

McCraty, R., Atkinson, M., Tiller, W. A., Rein, G., \& Watkins, A. D. (1995). The effects of emotions on short-term power spectrum analysis of heart rate variability. American Journal of Cardiology, 76, 1089-1093.

Munoz, M. L., van Roon, A., Riese, H., Thio, C., Oostenbroek, E., Westrik, I., ... Snieder, H. (2015). Validity of (ultra-)short recordings for heart rate variability measurements. PLoS One, 10(9), e0138921. doi: 10.1371/journal.pone.0138921

Muris, P., Meesters, C., Prierik, A., \& Kock, B. D. (2015). Good for the self: Self-compassion and other self-related construct in relation to symptoms of anxiety and depression in nonclinical youths. Journal of Child and Family Studies, 25(2), 607-617. doi: 10.1007/s10826-015-0235-2

Neff, K. (2011). Self-compassion: Stop beating yourself up and leave insecurity behind. New York: William Morris.

Neff, K. D. (2003). Development and validation of a scale to measure self-compassion. Self and Identity, 2, 223-250. doi: $10.1080 / 15298860309027$

Neff, K. D. (2004). How self-critical are you? Retrieved from: http://facesconferences.com/wp-content/uploads/2012/10/ Neff-Exercises_to_Increase_Self-Compassion.pdf

Neff, K. D. (2012). The science of self-compassion. In C. K. Germer \& R. D. Siegel (Eds.), Wisdom and compassion in psychotherapy: Deepening mindfulness in clinical practice (pp. 79-92). New York: Guilford Press.

Neff, K. D. (2017). Self-compassion guided meditations and exercises. Retrieved from: http://self-compassion.org/category/exercises/\#exercises Accessed: April 06, 2017.

Neff, K. D., \& Germer, C. K. (2013). A pilot study and randomized controlled trial of the mindful self-compassion program. Journal of Clinical Psychology, 69(1), 28-44. doi: 10.1002/jclp.21923

Neff, K. D., Kirkpatrick, K. L., \& Rude, S. S. (2007). Self-compassion and adaptive psychological functioning. Journal of Research in Personality, 41(1), 139-154. doi: 10.1016/j.jrp. 2006.03.004

Noguchi, K., Gel, Y., Brunner, E., \& Konietschke, F. (2012). nparLD: An R software package for the nonparametric analysis of longitudinal data in factorial experiments. Journal of Statistical Software, 50(12), 1-23. doi: 10.18637/jss.v050.i12

Nussinovitch, U., Elishkevitz, K. P., Katz, K., Nussinovitch, M., Segev, S., \& Volovitz, B. (2011). Reliability of ultrashort ECG indices for heart rate variability. Annals of Noninvasive Electrocardiology, 16, 117-122. doi: 10.1111/j.1542-474X. 2011.00417.x

O’Connor, R. C., \& Noyce, R. (2008). Personality and cognitive processes: Self-criticism and different types of rumination as predictors of suicidal ideation. Behaviour Research and Therapy, 46(3), 392-401. doi: 10.1016/ j.brat.2008.01.007

Palantini, P. (1999). Need for a revision of the normal limits of resting heart rate. Hypertension, 33(2), 622-625. doi: 10.1161/01.hyp.33.2.622

Park, G., \& Thayer, J. F. (2014). From the heart to the mind: cardiac vagal tone modulates top-down and bottom-up visual perception and attention to emotional stimuli. Frontiers in Psychology, 5, 278. doi: 10.3389/fpsyg.2014.00278

Pascual-Leone, A., Gillis, P., Singh, T., \& Andreescu, C. A. (2013). Erratum to: Problem anger in psychotherapy: An emotion-focused perspective on hate, rage and rejecting anger. Journal of Contemporary Psychotherapy, 43(2), 93103. doi: 10.1007/s10879-12-9228-2

Pascual-Leone, A., \& Greenberg, L. S. (2007). Emotional processing in experiential therapy: Why "the only way is through." Journal of Consulting and Clinical Psychology, 75(6), 885-887. doi: 10.1037/0022-006x.75.6.875

Pennebaker, J. W. (2017). Expressive writing in psychological science. Perspectives on Psychological Science, 13(2), 226229. doi: $10.1177 / 1745691617707315$

Pennebaker, J. W., \& Beall, S. K. (1986). Confronting a traumatic event: toward an understanding of inhibition and dis- 
ease. Journal of Abnormal Psychology, 95(3), 274-81. doi: $10.1037 / 0021-843 x .95 .3 .274$

Petrocchi, N., Ottaviani, C., \& Couyoumdjian, A. (2017). Compassion at the mirror: Exposure to a mirror increases the efficacy of a self-compassion manipulation in enhancing soothing positive affect and heart rate variability. The Journal of Positive Psychology, 12(6), 525-536. doi: 10.1080/17439760.2016.1209544

Pomeranz, B., Macaulay, R. J., Caudill, M., Kutz, I., Adam, D., \& Gordon, D. (1985). Assessment of autonomic function in humans by heart rate spectral analysis. American Journal of Physiology-Heart and Circulatory Physiology, 248(1). doi: 10.1152/ajpheart.1985.248.1.h151

Pool, R. (1989). Is healthy to be chaotic? Science, 243(4891), 604-607. doi: 10.1126/science. 2916117

Pöyhönen, M., Syväoja, S., Hartikainen, J., Roukonen, E., \& Takala, J. (2003). The effect of carbon dioxide, respiratory rate and tidal volume on human heart rate variability. Acta Anaesthesiologica Scandinavica, 48, 93-101. doi: 10.1111/j. 1399-6576.2004.00272.x

Praško, J., \& Prašková, H. (2007). Asertivitou proti stresu. Praha: Grada.

R Core Team (2013). $R$ : A language and environment for statistical computing. R Foundation for Statistical Computing, Vienna, Austria. Retrieved from: http://www.R-project.org/

Rockliff, H., Gilbert, P., \& McEwan, K. (2008). A pilot exploration of heart rate variability and salivary cortisol responses to compassion-focused imagery. Clinical Neuropsychiatry, 5(3), 132-139.

Rockliff, H., Karl, A., McEwan, K., Gilbert, J., Matos, M., \& Gilbert, P. (2011). Effects of intranasaloxytocin on compassion focused imagery. Emotion, 11, 1388-1396. doi: 10.1037/a0023861

Rockman, P., \& Hurley, A. (2015). Self-compassion and mindfulness. Toronto, ON: The Centre for Mindfulness Studies. Retrieved from: http://www.mindfulnessstudies.com/wpcontent/uploads/2015/09/Self-Compassion_and_Mindfulness.pdf

Rodriguez-Linares, L., Mendez, A. J., Lado, M. J., Olivieri, D. N., Vila, X. A., \& Gomez-Conde, I. (2011). An open source tool for heart rate variability spectral analysis. Computer Methods and Programs in Biomedicine, 103(1), 39-50. doi: 10.1016/j.cmpb.2010.05.012

Safer, D. L., \& Hugo, E. M. (2006). Designing a control for a behavioral group therapy. Behavior Therapy, 37(2), 120130. doi: 10.1016/j.beth.2005.06.001

Salahuddin, L., Cho, J., Jeong, M. G., \& Kim, D. (2007). Ultra short-term analysis of heart rate variability for monitoring mental stress in mobile settings. IEEE 29th International conference of the EMBS, Lyon, France. doi: 10.1109/ IEMBS.2007.4353378

Shahar, B., Carlin, E. R., Engle, D. E., Hegde, J., Szepsenwol, O., \& Arkowitz, H. (2012). A pilot investigation of emotionfocused two-chair dialogue intervention for self-criticism. Clinical Psychology and Psychotherapy, 6, 496-507. doi: 10.1002/cpp.762

Silverman, M. N., Heim, C. M., Nater, U. M., Marques, A. H., $\&$ Sternberg, E. M. (2010). Neuroendocrine and immune contributors to fatigue. $P M \& R, 2(5), 338-346$. doi: 10.1016/j.pmrj.2010.04.008

Simon-Thomas, E. R., Godzik, J., Castle, E., Antonenko, O., Ponz, A., Kogan, A., \& Keltner, D. J. (2011). An fMRI study of caring vs self-focusduring induced compassion and pride. Social Cognitive and Affective Neuroscience, 7(6), 635-648. doi: 10.1093/scan/nsr045

Singh, J. (1998). Heritability and heart rate variability: The Farmingham heart study. Journal of the American College of Cardiology, 31(2). doi: 10.1016/s0735-1097(97)84446-4

Smith, M. J. (1975). When I say no, I feel guilty. New York, NY, US: Dial Press/Random House.

Stellar, J., Feinberg, M., \& Keltner, D. (2014). When the selfish suffer: evidence for selective prosocial emotional and physiological responses for suffering egoists. Evolution and Human Behavior, 35(2), 140-147. doi: 10.1016/j.evolhumbehav.2013.12.001

Stellar, J. E., Cohen, A., Oveis, C., \& Keltner, D. (2015). Affective and physiological responding to the suffering of others: compassion and vagal activity. Journal of Personality and Social Psychology, 108(4), 572-585. doi: 10.1037/ pspi0000010

Svendsen, J. L., Osnes, B., Binder, P. E., Dundas, I., Visted, E., Nordy, H., ... Sørensen, L. (2016). Trait self-compassion reflects emotional flexibility through an association with high vagally mediated heart rate variability. Mindfulness, 7(5), 1103-13. doi: 10.1007/s12671-016-0549-1

Timulak, L. (2015). Transforming emotional pain in psychotherapy: An emotion-focused approach. Hove: Routledge.

Timulak, L., \& McElvaney, J. (2015). Emotion-focused therapy for generalized anxiety disorder: An overview or the model. Journal of Contemporaty Psychotherapy, 46(1), 41-52. doi: 10.1007/s10879-015-9310-7

Timulak, L., \& Pascual-Leone, A. (2014). New developments for case conceptualization in emotion-focused therapy. Clinical Psychology and Psychotherapy, 22(6), 619-36. doi: 10.1002/cpp. 1922

Whelton, W. J., \& Greenberg, L. S. (2005). Emotion in self-criticism. Personality and Individual Differences, 38, 15831595. doi: 10.1016/j.paid.2004.09.024

Yasuma, F., \& Hayano, J. (2004). Respiratory sinus arrhythmia: why does the heartbeat synchronize with respiratory rhythm? Chest, 125(2), 683-90. doi: 10.1378/chest. 125.2.683

Zessin, U., Dickhauser, O., \& Garbade, S. (2015). The relationship between self-compassion and well-being: A metaanalysis. Applied Psychology: Health and Well-Being, 7(3), 340-364. doi: 10.1111/aphw.12051

Zuroff, D. C., Santor, D. A., \& Mongrain, M. (2004). Conceptualizing and measuring personality vulnerability to depression: Comment on Coyne and Whiffen (1995). Psychological Bulletin, 130(3), 489-511. doi: 10.1037/00332909.130.3.489

Zwan, J., E., Wente, W., Huizink, A. C., \& Bruin, E. I. (2017). The effects of physical activity, mindfulness meditation, heart rate variability biofeedback on executive functioning, worrying and mindfulness. Applied Psychology and Biofeedback, 40(4), 257-268. doi: 10.1007/s10484-0159293-x 